2022 TheoLogica

An International Journal for Philosophy of Religion and Philosophical Theology

ORIGINAL PAPER

DOI: https://doi.org/10.14428/thl.v6i2.63473

\title{
Arguing for Atonement?
}

RICHARD BRIAN DAVIS

Tyndale University

rdavis@tyndale.ca

\begin{abstract}
According to William Lane Craig, to avoid compromising God's aseity we must embrace nominalism with respect to mathematical and logical objects. There are no numbers, propositions, possible worlds, properties, or relations. In this paper I argue that Craig's nominalism threatens to undermine his theological stance on the atonement.
\end{abstract}

Keywords: Abstract Objects, Aseity, Atonement, Nominalism, Platonism

According to one sort of nominalist-William Lane Craig prefers the term 'antirealist' 1 - there are no mathematical or logical objects: no numbers, propositions, possible worlds, properties, or relations. Everything whatsoever is a concrete object: either a substance or a trope. (Call this position NOMA: no mathematical objects.) Now I have a good deal of sympathy for this view, especially for the theological reasons Craig sets out related to divine aseity. Still, whether NOMA will ultimately carry the day (with classical theists) may well depend on how the details get filled in. In what follows I argue that Craig's nominalism threatens to undermine his position on the atonement.

In his work on penal substitution, Craig has advanced dozens of argumentssome of which at least are to be understood as deductively valid. Consider, for example, the Satisfaction Argument -in Craig's mind, a "persuasive argument for the conviction of Anselm and the Reformers that the satisfaction of divine justice is a necessary condition of salvation" (Craig 2018, 94). The argument goes as follows:

(1) Necessarily (Retributive justice is essential to God).

(2) Necessarily (If retributive justice is essential to God, then God justly punishes every sin).

(3) Necessarily (If God justly punishes every sin, then divine justice is satisfied).

(4) Therefore, necessarily (Divine justice is satisfied.)

\footnotetext{
${ }^{1}$ See William Lane Craig (2017, 13-14).
} 
(5) Therefore, necessarily (If some human beings are saved, divine justice is satisfied).

(1)-(3) are the premises. "From the three premises," Craig says, "(4) follows. Divine justice is satisfied so long as no sin goes unpunished." (Ibid.) Now by 'follows' here Craig means 'logically follows' or 'is entailed by'. Indeed, the argument from (1)-(3) to (4) is deductively valid - being an instance of (modal) modus ponens twice over. Also valid is the inference of (5) from (4). Thus, Craig comments:

(5) in turn follows, since any proposition implies a necessary truth. It also follows that if divine justice is not satisfied, then no human beings are saved; indeed, that it is impossible that any human beings are saved. (Ibid)

The notion of implication or entailment here is strict. A proposition $P$ strictly implies a proposition $Q$ just in case it is impossible that $P$ is true and $Q$ is false. Of course, if $Q$ is a necessary truth (e.g., the law of excluded middle), then not- $Q$ is a necessary falsehood; in which case the conjunction of any $P$ with not- $Q$ will be impossible. That is to say, any proposition $P$ strictly implies any necessary truth. (This is of course one of Lewis' infamous paradoxes of strict implication. ${ }^{2}$ )

\section{The World According to NOMA}

Now as we all learned at our mother's knee, a valid argument is one in which the premises entail or strictly imply the conclusion. A valid argument is such that (necessarily) if its premises are true, its conclusion is also true. And then given the truth of those premises, we can go on to say that the argument is not only valid but sound. Presumably then, a deductive proof will be a sound argument. It may well be more than that but certainly nothing less. ${ }^{3}$

\subsection{Propositional Truth}

So let's ask whether the premises of the Satisfaction Argument are true when viewed through the lens of NOMA. A prior question here: what sort of thing is a premise? On the canonical conception, premises are taken to be propositions: claims or assertions that represent things as being this way or that-true if they get things right and false if they don't. They can be believed or disbelieved. When, for example,

\footnotetext{
2 See C.I. Lewis and C.H. Langford (1959, 174-175).

${ }^{3}$ On this point, see the helpful discussion in George I. Mavrodes (1970, 29-35).
} 
I believe that retributive justice is essential to God, I don't believe that string of ink marks; I believe the content of what is inscribed on p. 94 of my copy of Craig's book, where premise (1) happens to be recorded. I believe the propositional truth communicated by that sequence of shapes. Propositions are not identical with the sentences (utterances or inscriptions) used to express them. Indeed, if Plantinga is right, they're not identical with concrete objects of any kind. ${ }^{4}$ On the canonical conception, they are abstract (or at least non-linguistic) entities.

According to Craig's NOMA view, however, "not only are there no propositions [in this sense], but there are no properties either. Therefore, there really isn't such an entity as truth" (Craig 2013, 362). But that implies (given the canonical conception) that there are no true premises. Indeed, the dialectical situation is even grimmer. For if premises and conclusions are best construed as propositions, and it turns out that there are none, then the Satisfaction Argument doesn't even exist. So much for arguing on behalf of penal substitution!

Not surprisingly, Craig has an answer to this line of criticism. He maintains that there is no good reason to believe there are any abstract objects. For the principle argument in their favour-the so-called Indispensability Argument-is an abject failure: "a piece of philosophical imperialism" (Craig 2017, 486). There is no need to descend into the mind numbing details here. ${ }^{5}$ Craig's point is that contrary to initial appearances, our assertively uttering/inscribing sentences containing singular terms (e.g., "the number 9 is odd"), or existentially quantified sentences (e.g., "there are numbers greater than $9^{\prime \prime}$ ) is by no means ontologically committing. There need be no referents for the singular terms used, or a real world of objects in the domain over which we are quantifying. Talk of numbers, propositions, properties, and the like is simply a façon de parler. We may regard it, if we like, as "metaphorical (figuralism) or make-believe (pretense theory) or just plain false (fictionalism)" (Craig 2017, 485).

Two initial comments. First, it is worth noting that Indispensability Arguments don't fail across the board, even if they fail in the case of abstract objects. For example, these instances of the general form of the argument appear to be perfectly in order:

(6) There are literally true existential sentences.

(7) If (6), then there are sentences.

So: (8) Sentences exist.

\footnotetext{
${ }^{4}$ For argument, see his Warrant and Proper Function (1993, 117-120). See also the discussion in Hilary Putnam, Philosophy of Logic (2011).

${ }^{5}$ For details aplenty, see God and Abstract Objects, ch. 3; see also Craig's more accessible, semipopular discussion in God Over All: Divine Aseity and the Challenge of Platonism (2016), chs. 6-7.
} 
Or again,

(9) This sentence is a concrete object.

(10) If (9), then there are concrete objects.

So: (11) Concrete objects exist.

My assertively uttering (/inscribing) (6) or (9) does indeed involve an ontological commitment on my part. I commit myself to the real existence of the very concrete sentences I find myself having uttered or inscribed.

Secondly, as Craig lays things out, for the classical theist at least, the Indispensability Argument for abstract objects fails primarily because she already knows there aren't any such things. For if there were, God would depend on them in crucial ways. And then given that aseity is an essential attribute of deity, it would follow that God didn't even exist. ${ }^{6}$ Fair enough: but believing in premises isn't a matter of metaphor, fiction, or make-believe. There are premises (in a metaphysically heavyweight sense) - for example, there are the ones figuring in the Satisfaction Argument. If they're not abstract entities, what are they? Further, if we don't believe they are substantially true (there being no such property), what is it that recommends them? Surely the premises of a proof-or even just a good argument-must have some positive alethic status.

\subsection{Sentential Correspondence}

Now if I understand Craig here, he doesn't mean to deny that there are premises (/conclusions). Of course not. What he denies is that these are abstract, uncreated truth-bearers. Instead, the anti-Platonist "can happily admit the existence of sentence tokens as truth-bearers, for these are clearly created, concrete objects" (Craig 2013, 355). Happily, I don't know. For if sentences are tokens, won't there be types of which they are tokens? (A token without a type is like an effect without a cause: hard to make sense of at best.) Arguably, however, sentence types are abstract patterns or forms: just what the proponent of NOMA was hoping to avoid.

I also don't think Craig wants to deny that there is a sense in which premises (/conclusions) can be true. To be sure, as a deflationary nominalist, he rejects the idea that 'is true' predicates a substantial (abstract) truth property of a sentence. This is easily avoided. For we can "descend," if we like, from talk of premises being true to

\footnotetext{
${ }^{6}$ See Craig $(2016,43)$. Compare also: "the ultimate motivation behind our inquiry into anti-realist theories of abstract objects is theological" (Craig 2017, 229).
} 
simply asserting them. We need only drop the alethic add-on 'is true'. Instead of saying of a sentence token $S$, "It's true," we just declare " $S$ " and leave it at that. But unless we already know there aren't any properties, this move is bound to strike the realist as little more than a piece of semantic imperialism. How does it do away with truth simpliciter?

In fact, it doesn't. In the first place, notice that when we make our semantic "descent," we don't conclude by merely affirming the sentence (/premise) in question. "Rather than talk about truth," Craig says, "we can descend semantically and truly affirm" it (2017, 194; emphasis added). So we haven't really stopped talking about truth. We've only shifted from speaking of it on one level (a true sentence token) to speaking of it on another (a true affirmation of that token).

Second, Craig tells us explicitly that his descent deflationism "is compatible with truth as correspondence." For "statements directly asserted" [e.g., (1)-(5) above] are descriptive of the world as it actually is" (2013, 355; emphasis added). ${ }^{7}$ But there is a proviso. Correspondence must be cashed out holistically-in terms of whole sentences:

[C]orrespondence may be taken to obtain between a sentence as a whole and the world. Such holistic correspondence is expressed by Tarski bi conditionals. A deflationary view of truth ... need understand no more by the notion of truth as correspondence than that " $S$ " is true if and only if $S$. That is all there is to truth as correspondence. (Craig 2017, 467-468)

Here I believe there is good news mixed with bad. The good news is that on this view we can say of the sentences comprising the Satisfaction Argument: they correspond with reality. (After all, what kind of argument would it be, if ex hypothesi its premises failed to describe the world correctly?) The bad news is that the Tarski biconditionals are not "all there is to truth as correspondence," and coupled with NOMA this fact makes trouble for the argument's soundness. We can see this as follows.

\footnotetext{
${ }^{7}$ Compare Craig's response to Trenton Merricks's claim that (e.g.) counterfactuals of freedom fail to correspond to existing entities: "it seems to me obvious that such truths [i.e., true sentences] do tell us about how the world is and so can be said to correspond with reality" $(2017,472)$.
} 


\section{Objections}

\subsection{The Premises}

Consider the first premise of the Satisfaction Argument:

(1) Necessarily (Retributive justice is essential to God).

This premise is compound; it is comprised of a sentence token (the material inside the brackets) prefixed by a modal operator: 'necessarily'. Here the necessity involved is presumably a de dicto logical necessity. Given a deflationary view of truth, of course, we can't say that what is necessary here is the sentence token's being true. Nevertheless, Craig is directly asserting it to describe the world as it actually is. ${ }^{8}$ Thus it can be truly said (by his lights) to correspond with reality. We may therefore read premise (1) as follows:

$\left(1^{*}\right)$ Necessarily, the sentence token "Retributive justice is essential to God" corresponds with reality. ${ }^{9}$

Still, there is something more to correspondence than just removing some quotation marks. The sequence of shapes (inside those quotes) must state what is the case; it must describe the world as it actually is. Craig concurs: "A statement $S$ is true," he says, "if and only if what $S$ states is the case" (2017, 469; emphasis added). So we can sharpen $\left(1^{*}\right)$ to read:

\footnotetext{
${ }^{8}$ Craig has affirmed this in discussion. See ReasonableFaithOrg, "EPS Panel Discussion: Craig's Nominalism and the Atonement." YouTube video, 2:11:02. August 31, 2021. https://youtu.be/poPTEHws9Qo. Craig hastens to add that he doesn't believe that his asserting (1) commits him to the existence of that premise. See in particular 1:46.10 to 1:46.55.

${ }^{9}$ Objection: the move from (1) to $\left(1^{*}\right)$ is invalid. In premise (1), the sentence token "Retributive justice is essential to God" is presumably to be understood as expressing the proposition we take it to express in the actual world. By contrast, in $\left(1^{*}\right)$ that same sentence token isn't indexed to the actual world. Instead, as an anonymous referee puts it, "it can link up with whatever proposition or property one likes."

Reply: this objection isn't strictly to the point. In fact, it depends on assumptions Craig himself would reject-e.g., that sentence tokens can state, express, or be linked up with propositions. On his view, sentence tokens can do no such thing, since there are no propositions. Here $\left(1^{*}\right)$ isn't an entailment of (1); rather, it is a reading or interpretation of Craig's first premise in light of the things he tells us about sentence tokens, propositional truth, correspondence, and the like.
} 
$\left(1^{* *}\right)$ Necessarily, the sentence token "Retributive justice is essential to God" corresponds to the state of affairs ${ }^{10}$ which (as things in fact stand) it states to be the case: retributive justice is essential to God.

All that remains is to decide what is meant, here, by 'necessarily'. Craig doesn't have a full-blown theory of modality; however, he does tell us how to read a statement such as "Necessarily, $2+2=4$." There is "no trouble," he says, "understanding what this simple sentence means; for example, that $2+2$ could not but be $4^{\prime \prime}(2017,194)$. So we can take $\left(1^{* *}\right)$ as

$\left(1^{* * *}\right)$ The sentence token "Retributive justice is essential to God" could not fail to correspond to the state of affairs which (as things in fact stand) it states to be the case: retributive justice is essential to God.

Unfortunately, this view of premise (1) - under the lens of NOMA, as it were-has several unhappy results. Note first that if $(1)$ implies $\left(1^{* * *}\right)$, and $\left(1^{* * *}\right)$ is false, then so is the argument's first premise. And strictly speaking, $\left(1^{* * *}\right)$ is false. The series of marks "Retributive justice is essential to God" (" $R$ " for short) could very well have failed to correspond to the (actual) state of affairs retributive justice is essential to God. It could have failed to correspond, for example, by failing to exist. Sentences, after all, are concrete and contingent; unlike God, they don't exist by a necessity of their own nature.

You might object that by "could not fail to correspond" we don't mean "fail to correspond simpliciter"; we mean only that $R$ "couldn't both exist and fail to correspond." But this suggestion doesn't help. The problem, fundamentally, is that a series of marks-like $R$-doesn't in itself describe anything. It doesn't state what is the case. Hence, it doesn't in itself correspond with reality. Individual words (e.g., proper names) don't refer just by virtue of being words. Rather, on Craig's view, "it is persons who refer to things by means of their words, so that words at best refer only in a derivative sense, if at all" $(2016,135)$. Well, it seems to me the same might be said for sentences as a whole. A sentence like $R$ states what is the case but only if there are speakers or writers who thus $u s e$ it. But if so, $R$ could certainly exist but fail to correspond.

10 'State of affairs': the concrete fact to which a true sentence corresponds. A fact, in this sense, is not to be confused with a Plantinga-style states of affairs, which, like a proposition, is an abstract object: obtaining or not depending on how things stand in the world. See Alvin Plantinga (1974, 4546). On the distinction between abstract and concrete states of affairs, see William F. Vallicella (2000, 237). 
Think, for example, of a world ${ }^{11}$ in which $R$ exists but there are no language users. In such a world, $R$ simply won't have anything to say. It won't state anything; so it won't correspond with any state of affairs. Nor will it help matters to add human beings to the equation. For it is entirely possible that they might employ $R$ to describe a vastly different state of affairs - say, Plantinga's being a Harlequin romance novelistrather than the one it does in fact describe. In either case, then, $R$ will exist alright; but it will fail to correspond as $\left(1^{* * *}\right)$ prescribes.

It seems to me, therefore, that premise (1) is false simply by virtue of what a premise would be if NOMA anti-realism were true. And this general line of criticism extends to the other premises as well.

\subsection{Validity}

This brings us to a related problem. An inference from premises to conclusion is valid just in case it obeys the laws of logic. As C. I. Lewis remarks, our proofs "depend" on these laws or principles; they are "presumed in demonstrations" (Lewis and Lanford 1959, 115-116). Exactly so. The Satisfaction Argument relies on two such laws. Where $P$ and $Q$ are sentence tokens:

L1: If $((P$ implies $Q)$ and $P)$, then $Q$.

L2: $P$ strictly implies $Q$ if and only if it is impossible that $P$ and not- $Q$.

As we noted above, the first is modus ponens, and is used to derive (4) from (1)-(3). The second validates the inference from (4) to (5). Now intuitively, a valid deductive argument is one in which the premises strictly imply the conclusion. Translated into NOMA talk: it is an argument in which the conclusion cannot but follow from the premises.

Now even if (in the interests of charity) we restrict our attention to those worlds in which the sentences comprising the Satisfaction Argument exist, it seems to me perfectly possible (given NOMA) that among these worlds there be some in which its conclusion doesn't follow from its premises. For it's perfectly possible that among these worlds, one or more of our logical laws (i.e., L1 or L2 qua sentence tokens) doesn't exist, and is therefore unavailable to validate the requisite inferences. You might as well set your logic students a test in which they must construct a series of

${ }^{11}$ According to Craig's brand of NOMA, although there are no possible worlds, we can nevertheless "employ the useful fiction of possible worlds to provide the usual semantics for stating the truth conditions of such a sentence" $(2017,194)$. 
natural deduction proofs in Copi-style logic, but without the aid of the inference and equivalence rules they've been using all semester. It's a hopeless business.

But here the proponent of NOMA is not without reply. Reaching back to those far-off fabulous days when Molinism was all the rage in the journals: many of you are aware that on Craig's Molinist scheme, there are three "logical moments" in the structure of God's knowledge - the first of which is relevant for our purposes. Craig describes it as follows:

In the first moment is God's knowledge of all necessary truths, for example, the laws of logic. God does not make such statements true by willing them to be true . . Rather, statements which are true in this moment are true by virtue of the nature of God himself and so do not depend on his will. He knows them to be true by his very nature, and so this first moment of divine knowledge is called natural knowledge ... God could not lack this knowledge and still be God; the content of God's natural knowledge is essential to him. (Craig 2000, 129)

Here we learn that laws of logic are necessary truths: statements (or sentences) ${ }^{12}$ true by virtue of their corresponding to "the nature of God himself." It is essential to God that he "knows them to be true." It follows, if God is a logically necessary being, that he knows these true sentences in every possible world. No need to worry, therefore, about worlds in which L1 and L2 fail to exist, and consequently in which the conclusion of the Satisfaction Argument doesn't follow from its premises.

This is a fascinating suggestion. But there is a price to be paid; I'll leave it to you to decide whether the price is right. On this account, it will be necessary (contrary to intuition) that there are concrete sentences. If God is essentially omniscient, for every world in which he exists (namely, every world whatsoever), there will be all the sentences he knows to be true. Further, some of these (say, the logical laws undergirding the Satisfaction Argument) will be such that they couldn't fail to correspond to reality. But if, as Craig holds, sentence tokens can correspond only if there are persons who use them to state or describe what is (could be, or must be) the case, then since there are necessarily corresponding sentences, it will be necessary that there are persons. On a theistic view, of course, it will be implausible in excelsis to suppose that it is human persons who thus use these sentences for the purpose of stating things. After all, it is hardly necessary that God create the likes of us. But neither is it plausible to suppose that God, though a necessarily existing

\footnotetext{
${ }^{12}$ In his work on abstract objects, Craig doesn't sharply distinguish statements from sentences, but tends to use these terms interchangeably.
} 
person, is obliged to create and then use physical shapes or sounds to ensure an ample supply of sentences he can know to be true lest he cease to exist!

For my part, however, I cannot help but think there are (in a heavyweight sense) necessary truths. Indeed, there are seven at least: the five featured in the Satisfaction Argument, along with the two laws of logic that make it go. However, I also think Craig is right (or nearly right) about abstract objects; they flout God's aseity. Thus, we shouldn't think of the seven as independent, uncreated, Platonic Forms. But neither (so we've seen) are they plausibly construed as sentence tokens.

The difficulties attending these ontological extremes largely fall off, if the theist makes appeal to what she already knows: that God (a perfect epistemic agent) cannot but think of the seven as true. Indeed, we might even say that the seven just are God's thoughts: thoughts "true by virtue of the nature of God himself"; hence, thoughts about what must be the case in any world. Of course, to avail ourselves of this via media, we must allow that there is a God and that he has thoughts. However, while the psalmist (David) declares

How precious to me are your thoughts, O God! How vast is the sum of them! (Psalm 139:17),

Craig demurs. While divine conceptualism (according to which propositions are taken to be God's thoughts) is a decent "fallback position," 13 in the final analysis there is simply no reason to think that God has thoughts. ${ }^{14}$ Like abstract object talk, talk of God's thoughts is a mere façon de parler. Thus Craig:

God thinks that Columbus discovers the New World in 1492, and so we speak of God's thought that Columbus discovers the New World in 1492. There is no more reason to add thoughts to our ontological inventory of things than hesitations or plans. (2017, 200)

When we speak, for example, of God's plan for our lives, or our hesitations about dispelling a protest by invoking an Emergencies Act, it hardly follows (says Craig) that we've committed ourselves to an ontology of plans and hesitations. Perhaps so;

\footnotetext{
${ }^{13}$ Thus Craig: "While Conceptualism such as is defended by Rich Davis remains for me a fallback position should all forms of Nominalism fail, I think that the alternatives afforded by Nominalism are far from exhausted" $(2011,306)$. The appeal to conceptualism as a fallback position is reiterated in God and Abstract Objects (2017, 201), and God Over All (2016, 206-207).

${ }^{14}$ For Craig's various criticisms of conceptualism, see God and Abstract Objects (2017, 201-211), and God Over All (2016, 84-95).
} 
but would the same thing go for thoughts? I should think not. We don't add them to our ontological inventory because we're committed to believing in the things we talk about. Not one bit. We take our thoughts to be real because we ourselves have them, and we're directly acquainted with that fact.

But what about in God's case? Could it really be that I have the thoughts that there is a God, that Jesus is the Messiah, and that William Lane Craig wrote God Over All, but God has none of these thoughts? I find that incredible. Yet it does seem to represent Craig's settled opinion on the matter. "The anti-realist," he says, "will hold that God thinks all the things that the conceptualist says He does, but the anti-realist will not reify God's thinking into objects which exist in addition to God Himself" (2016, 83). For my part, I can only say that God's thinking about (say) his own existence, while not having any thoughts at all on the matter, seems an incoherent suggestion.

By way of conclusion then: we have the Satisfaction Argument before us. If it is an argument, it must have premises and a conclusion. If it is a sound argument, its premises must be true, and they must collectively entail (via logical laws) the truth of its conclusion. Whether Craig's nominalism can deliver on these fronts remains to be seen. On his way of thinking, there are no premises, conclusions, or logical laws construed as abstract (Platonic) propositions or divine thoughts. But neither, so we've argued, can sentence tokens take up the slack. So where does that leave the Satisfaction argument? Craig has described it as a "persuasive argument." The more fundamental question here, I believe, is whether (given his nominalism) it can even be said to exist.

\section{Bibliography}

Craig, William Lane. 2018. The Atonement. Cambridge: Cambridge University Press. https://doi.org/10.1017/9781108558020.

Craig, William Lane. 2017. God and Abstract Objects, The Coherence of Theism: Aseity. Springer International Publishing. https://doi.org/10.1007/978-3-319-55384-9.

Craig, William Lane. 2016. God Over All: Divine Aseity and the Challenge of Platonism. Oxford: Oxford University Press.

https://doi.org/10.1093/acprof:oso/9780198786887.001.0001.

Craig, William Lane. 2013. “Propositional Truth - Who Needs It?" Philosophia Christi 15:2: 355-364. https://doi.org/10.5840/pc201315232.

Craig, William Lane. 2011. "A Nominalist Perspective on God and Abstract Objects", Philosophia Christi 13:2: 305-318. https://doi.org/10.5840/pc201113228. 
Craig, William Lane. 2000. The Only Wise God: The Compatibility of Divine Foreknowledge and Human Freedom. Eugene, OR: Wipf and Stock Publishers.

Lewis, C. I. and C. H. Langford. 1959. Symbolic Logic, 2d. ed. New York: Dover Publications.

Mavrodes, George I. 1970. Belief in God: A Study in the Epistemology of Religion. Washington, DC: University Press of America.

Plantinga, Alvin. 1993. Warrant and Proper Function. New York: Oxford University Press. https://doi.org/10.1093/0195078640.001.0001.

Plantinga, Alvin. 1974. The Nature of Necessity. Oxford: Clarendon Press. https://doi.org/10.1093/0198244142.001.0001.

Putnam, Hilary. 2011. Philosophy of Logic. London: Routledge. (Original work published in 1971)

ReasonableFaithOrg. 2021. EPS Panel Discussion: Craig's Nominalism and the Atonement [Video]. YouTube. https://youtu.be/poPTEHws9Qo.

Vallicella, William F. 2000. "Three Conceptions of States of Affairs", Nous 34:2: 237259. https://doi.org/10.1111/0029-4624.00209.

Published Online: February 28, 2022 